\title{
La Fuente del Alacrán (Los Brianes, Corvera): De manantial de uso público a mina privada
}

\author{
The Source of The Alacrán (Los Brianes, Corvera): \\ From spring of public use to private mine
}

\author{
Gregorio CASTEJón Porcel \\ Universidad de Alicante \\ Gregorio RABAL SAURA \\ $\operatorname{SOMA}$ *
}

\begin{abstract}
Resumen: Analizamos las características físicas e históricas del tradicional aprovechamiento humano y agropecuario de la Fuente del Alacrán, surgencia que se localizaba al norte del caserío de Los Brianes del Partido de Corvera (Murcia), en el lecho de la llamada Rambla del Escobedo, antaño conocida como Rambla de la Fuente del Alacrán. Las evidencias físicas, apreciadas mediante el trabajo de campo, manifiestan la presencia de hasta cuatro sistemas distintos de aprovisionamiento de agua en el citado cauce desde hace siglos. Sin embargo, aunque se abordan todas las canalizaciones halladas, por la mejor conservación de la obra y la mayor disponibilidad de documentación histórica, se estudia aquí fundamentalmente la que se corresponde con una mina de agua construida a mitad del siglo XIX por Nicolás Dato Rosique como método de abastecimiento de su hacienda de Los Brianes. De este modo, se añade al inventario regional otro sistema tradicional de captación de aguas subálveas en medios semiáridos en los que las galerías subterráneas, con o sin lumbreras, completaban los escasos recursos hídricos existentes.
\end{abstract}

Palabras clave: Manantial; mina de agua; acequia; Los Brianes; Corvera; Murcia.

\begin{abstract}
We analyze the physical and historical characteristics of the traditional human and agricultural use of the Fuente del Alacrán, a water source that was located north of the hamlet of Los Brianes in the Corvera district (Murcia), on the bed of the so-called Rambla del Escobedo, once known as Rambla de la Fuente del Alacrán. The physical evidence appreciated through fieldwork shows the presence of up to four different systems of water supply in the aforementioned riverbed for centuries. However, although all the channellings found are addressed, due to the better conservation of the work and the greater availability of historical documentation, we study here fundamentally the one that corresponds to a water mine built in the middle of the 19th century by Nicolás Dato Rosique as supply method of his state in Los Brianes. In this way, it is added to the regional inventory another traditional system for capturing sub-surface waters in semi-arid environments where the underground galleries, with or without luminaries, completed the scarce water resources.
\end{abstract}

Keywords: Spring; Water Mine; Irrigation Ditch; Los Brianes; Corvera; Murcia.

Recibido: 14, marzo, 2018. Aceptado: 15, mayo, 2018.

Email: gregorio.castejon@ua.es. Miembro de GIECRYAL, becario FPU. Departamento de Geografía Humana, Universidad de Alicante. Email: gregoriorabal@murciaeduca.es. Sociedad Murciana de Antropología. 


\section{INTRODUCCIÓN}

El aprovisionamiento de agua para el consumo humano y el desarrollo de las actividades de subsistencia, como la agricultura o la ganadería, han sido una meta milenaria por la que han luchado los pobladores de cualquier parte del mundo. Y lo han hecho, desde tiempos remotos, ejecutando ingeniosas y complejas soluciones técnicas que permitieron obtener el agua, tanto del subsuelo como de la superficie terrestre, no sin gran esfuerzo y aplicando los conocimientos sobre el territorio y el marco geográfico en el que se insertaban. Por ello, no es extraño que en un rincón situado en el piedemonte sur de la Sierra de Carrascoy, ubicado dentro del municipio de Murcia (Región de Murcia, España), sus habitantes hicieran uso, tanto para el abastecimiento propio como el de sus rebaños, así como para el regadío de los terrenos acondicionados para la explotación agrícola, de una surgencia a la que se denominó Fuente del Alacrán, cuyas aguas, según los datos disponibles, fueron utilizadas con tal fin durante siglos.

Este recurso, circunscrito posteriormente a la llamada Hacienda de Los Brianes y reacondicionado como mina filtrante a mediados del siglo XIX, se convirtió, durante largo tiempo, en un capital constante empleado por el dueño y arrendatarios de las parcelas de esta extensa propiedad, en la que, disponiendo de este privilegiado manantial y de las aguas derivadas de las escorrentías superficiales en episodios de lluvia, se lograban tanto producciones de cultivos de secano apoyados con agua, como otras de productos exclusivamente de regadío. Esta riqueza hídrica y la suficiencia de los terrenos que conformaban la citada heredad, permitió un desarrollo notable de la finca, acorde a la evolución económica y social del referido hacendado, del que existen notables referencias en la prensa de la época. Así, la infraestructura hidráulica ejecutada por Nicolás Dato Rosique en 1858, captó las aguas del subálveo de la Rambla del Escobedo - llamada antaño de Rambla de la Fuente del Alacrán-, conduciéndolas, mediante un caño, hasta una balsa circular desde la que se realizaba su distribución al resto de la propiedad.

La aplicación técnica del citado recurso de ingeniería hidráulica para obtener caudales de exiguos veneros de agua fue utilizada, tanto con anterioridad como de forma posterior, en otros lugares del amplio y árido Campo de Cartagena cuyos sistemas han sido estudiados por Gómez Espín et al. (2007), Egea Vivancos y Arias Ferrer (2007), Sánchez Martínez (2007), Gómez Espín et al. (2012), Castejón Porcel (2014 y 2015), Aranda Mercader (2014) y Martínez Hernández (2016). Del mismo modo, existen numerosas obras de tipología similar implantadas en el resto del territorio de la Región de Murcia que han sido analizadas, preferentemente, en las investigaciones llevadas a cabo por Encarnación Gil Meseguer y José M. Gómez Espín desde los inicios de los años noventa del siglo 
pasado hasta fechas recientes, tanto de forma individual como en colaboración con otros investigadores como Ignacio Aliaga Sola, José Antonio López Fernández, Ramón Martínez Medina, Alfredo Pérez Morales, Víctor Martínez Lucas, José Antonio Albaladejo García y Ramón García Marín.

En el presente trabajo se expone un nuevo ejemplo del uso de esta tipología de sistemas de captación de aguas subálveas en el territorio murciano, quedando constancia de su mayor profusión en los siglos XVIII y XIX gracias a la aplicación de las nuevas técnicas de ingeniería minera y al incremento de la riqueza de los propietarios de las grandes haciendas, gracias al auge económico derivado de la producción de la seda y la minería. Además, sumado al análisis de este sistema concreto, se presentan los restos de otras tres canalizaciones visibles en el cauce de esta misma rambla que debieron abastecer, igualmente, a los residentes del paraje indicado en una época anterior a la construcción de la citada galería. En este sentido, este pudiera ser el origen primitivo de la que se conoció como Fuente del Alacrán en una época anterior a aquella en la que Nicolás Dato Rosique realizó los trabajos para abrir la galería.

\section{2. ÁREA DE ESTUDIO}

En la mitad occidental de la solana del Parque Regional de El Valle y Carrascoy, concretamente en el territorio que forma parte del Partido de Corvera (municipio de Murcia), se encuentra, en su sector norte, una pequeña alineación montañosa conocida como Sierra del Puerto, en cuya cara sur serpentea, entre los resaltes topográficos del Cabezo del Rayo (al oeste) y El Miravete (al este), la Rambla del Escobedo, antiguamente conocida como Rambla de la Fuente del Alacrán, cabecera de la Rambla del Ciprés. En este paraje, prácticamente al inicio del citado cauce, se conoce, desde hace siglos, la existencia de la llamada Fuente del Alacrán, surgencia natural de la que antaño se abastecían los vecinos del entorno y de la cercana población de Corvera, así como también todos aquellos que tomaban esta ruta que recorría el piedemonte de la preindicada línea serrana en su camino hacia Murcia o como paso desde la capital regional hacia otros puntos al sur del valle del Guadalentín-Segura.

El área de estudio (Figura 1) se enmarca en un territorio árido de condiciones climáticas marcadas por la escasez de lluvias, lo que limita la presencia de una masa forestal importante; si bien, al estar a una cota elevada (400-470 m), en el inicio del glacis que une la citada sierra con la llanura del Campo de Cartagena, existe una tupida masa de matorral y monte bajo salpicada de pinos, formación vegetal típica mediterránea. La propia indigencia pluviométrica condiciona, además, la inexistencia de cursos fluviales permanentes que permitieran 


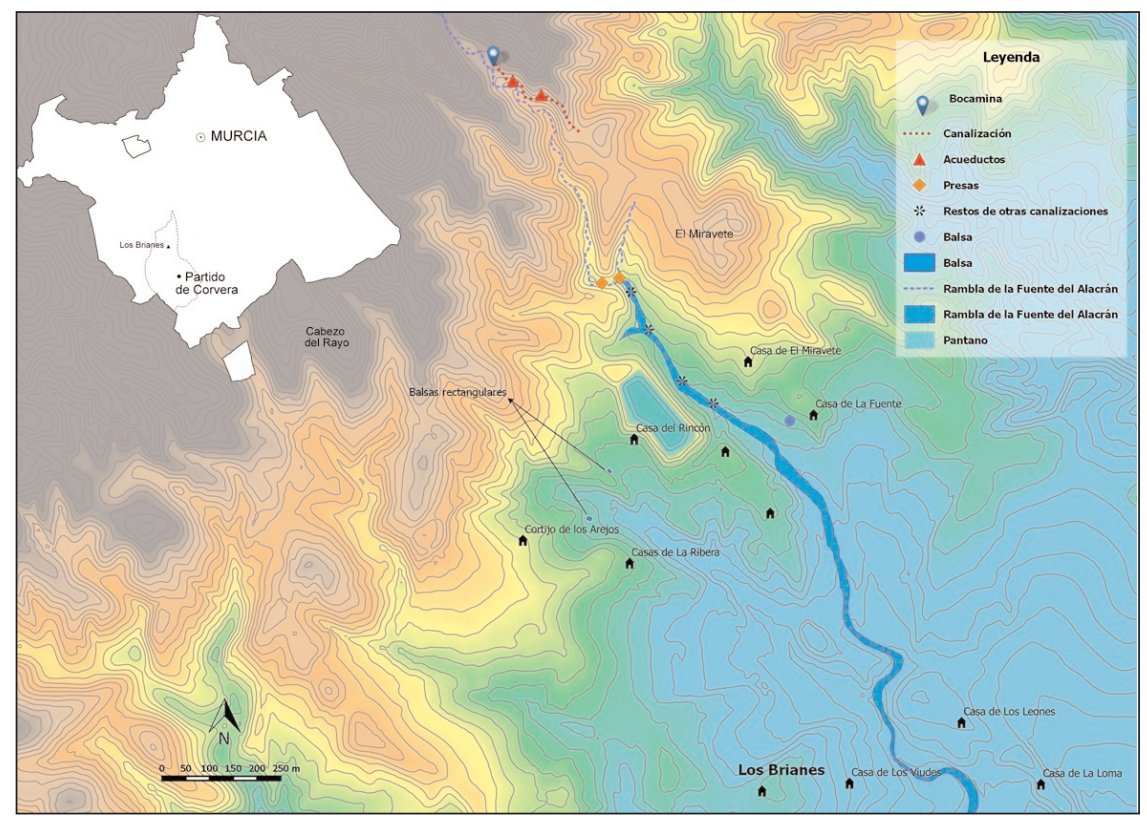

Figura 1. Área de estudio (elaboración propia)

un abastecimiento hídrico continuado de la población en épocas pretéritas, lo que determina que la red hidrográfica esté compuesta por ramblas, cauces de caudal efímero en episodios de lluvias abundantes que mantienen, en algunos momentos puntuales, un caudal casi testimonial tras intensas precipitaciones (Castejón y Rabal, 2018).

Demográficamente, pese a que en el entorno del indicado manantial no se erigió un núcleo habitado muy numeroso, sí que es cierto que existió un conjunto de viviendas diseminadas conocidas como Casa del Miravete, Casa del Rincón, Casa de la Rivera, y la más importante, la Casa de la Fuente. Además, al sur y rodeado por la Casa de los Viudes, la Casa de los Leones y la Casa de la Loma, se encontraba el caserío de Los Brianes, apelativo utilizado, hasta día de hoy, como topónimo para designar el lugar en el que se haya la citada fuente; casalicio de vital trascendencia en la historia del aprovechamiento hídrico sobre el que versa este trabajo y originado a raíz de una propiedad privada. De este modo, es cierto que la existencia de agua en la zona pudo actuar como foco de atracción de población, así como la presencia de una gran propiedad perteneciente a una familia con recursos que arrendaba parte de sus tierras a labradores y jornaleros del espacio contiguo a la misma. Con todo, administrativamente, el citado conjunto 
de viviendas rurales está incluido en el Partido de Corvera, delimitación cuya cabecera está representada por la localidad del mismo nombre, situada algo más alejada de falda de la Sierra de Carrascoy, circunscrita al territorio regido por el municipio de Murcia.

\section{LA FUENTE DEL ALACRÁN Y LOS BRIANES EN LA HISTORIA}

En el territorio comprendido por el piedemonte de Carrascoy y su entorno, se tiene constancia de la presencia de pobladores desde época argárica, si bien es cierto que es en la época romana y, sobre todo, en el periodo árabe, cuando los asentamientos son más numerosos, como así lo atestiguan los diferentes yacimientos arqueológicos registrados.

En este último caso, la economía elemental de los musulmanes asentados se basaba en la ganadería y en el cultivo extensivo de secano y, cuando era posible, el regadío mediante la aplicación de las aguas de boqueras, aljibes, pozos y, posiblemente, minados. Esta huella árabe está presente en los primeros repartimientos realizados por el rey castellano Alfonso X El Sabio en el siglo XIII tras la toma de Murcia. En estas concesiones, la presencia de nombres islámicos, tanto de propietarios como de parajes y elementos destacados, es una constante (Torres, 1960), lo que consolida la presencia del pueblo andalusí en el territorio de estudio. La llegada de los repobladores cristianos altera las denominaciones de los lugares y casas, estableciéndose en este espacio campestre de cultivo de secano extensivo y caza, familias cuyos apellidos han quedado reflejados en la toponimia de la comarca, como es el caso de Los Corvera, entre muchos otros. No obstante, pese a la repoblación, la emigración de los mudéjares y la inseguridad del territorio provocó que durante esta centuria se dé un considerable abandono de los cultivos y el retraimiento de las explotaciones agrarias, prácticamente restringidas a zonas con posibilidad de riego constante, es decir, cerca de los ríos. Esta situación se prolongó incluso durante el siglo XIV, cuando se inicia un nuevo proceso de concesión de tierras que continuó en los siglos XV y XVI. En estas últimas donaciones hechas por el concejo murciano, se citan parajes como: Rambla de Corvera, Senda de Corvera, Balseta de Corvera y Camino de Corvera (Molina, 1989), lo que manifiesta la consolidación de este enclave como núcleo poblacional habitado y pone de relieve el resultado del avance colonizador sobre la llanura del Campo de Murcia. Con todo, no será hasta el siglo XVIII cuando el partido, orgánica y administrativamente, pase a ser considerado como un lugar de señorío con alcalde pedáneo encuadrado dentro del Corregimiento de Murcia. El incremento de su influencia durante la centuria fue tal que en 1772 se determinó que quedarán a su cargo la administración política de las diputaciones de Los 
Martínez, Campuzano, Balsa de Aledo, Baños y Mendigo, Lo Jurado, Ventanas, Valladolises, Balsapintada, Lobosillo, Truyols y Doña Lucía o San Antonio; situación que se vio alterada hacia 1834, cuando todo el territorio pasa a depender de nuevo de Murcia.

Entre los distintos caseríos que salpican el área comprendida por el Partido de Corvera, el de Los Brianes es el que se analiza en este trabajo debido a la localización en el mismo del sistema de la Fuente del Alacrán. Históricamente, existen escasas referencias relativas tanto a este manantial como al citado caserío, como también lo son aquellas que aluden a la Casa de la Fuente, vivienda que posiblemente sería propiedad del constructor de la mina de agua y junto a la cual se encuentra la balsa receptora de la captación. Belda Navarro (1975) señaló en su día la presencia de indicios que, sin ser determinantes, evidenciaban la posible presencia en el entorno de la indicada surgencia de una villa romana, hablando, específicamente, del hallazgo de fragmentos cerámicos, algunos de sigillata sudgallica y clara, uno de ellos con decoración floral. En relación a ello, cabe decir que la localización de asentamientos romanos en zonas próximas a las ramblas del piedemonte de la solana de Carrascoy y el conjunto del Campo de Cartagena es una cuestión contrastada (García 2009-2010; Ramallo y Arana, 1984). Hecho que, junto con lo expuesto, hace plausible la existencia de una instalación de esta época en el entorno de estudio, si bien no se cuenta con evidencias físicas o documentales que ilustren esta teoría.

El déficit de referencias conocidas se mantiene en época medieval, hasta el punto de que la Fuente del Alacrán no aparece mencionada en el Repartimiento de Murcia (Torres, 1960), al contrario de lo que ocurre con otros manantiales del Campo de Murcia, como es el caso de la cercana Fuente de La Murta, citada en numerosas concesiones de tierras efectuadas en siglos posteriores, la más antigua fechada en 1465 y en la que tampoco aparece el referido manantial (Molina, 1989). Esto hace pensar en la posibilidad de que la indicada fuente no existiese por entonces o no se conociese en dicho momento, circunstancia poco probable si se tienen en cuenta las detalladas localizaciones geográficas señaladas en el documento. No obstante, la presencia de otras tres canalizaciones en el cauce, muy probablemente anteriores a la época de construcción de la mina de agua, hace que nos planteemos que la cronología de las mismas haya de retrotraerse, con toda probabilidad, a época medieval, atendiendo a sus características físicas. Sin duda, un análisis arqueológico exhaustivo del entorno de estas, podría arrojar luz sobre esta cuestión, permitiendo una datación certera de los restos existentes.

Otro factor importante es conocer el origen del caserío de Los Brianes y quién o quiénes pudieron ser aquellos cuyo apellido se asoció a este paraje del Campo de Murcia. En este sentido, según la información recabada, la denomina- 
ción del lugar podría estar relacionada con la existencia en él, en algún momento, de propiedades pertenecientes a la familia Brian, antropónimo que, parece ser, dio nombre al lugar. No obstante, en las donaciones realizadas por el concejo murciano desde el siglo XIII no aparece citado ningún colono con este apellido, si bien, existen algunas referencias a Brianes en Murcia tanto en el siglo XV como en el XVI. En el primer caso, se conoce la presencia en la ciudad del bachiller Bartolomé Brian, ${ }^{1}$ el cual estaba casado con una sobrina de Vozmediano de Arróniz, regidor de Murcia (Owens, 1980), y fue el canónigo fundador, en 1440, de la capilla de la Catedral a la que dio nombre su apellido (Belda y Hernández, 2006; García, 1980). En esta misma centuria, según la Relación de donaciones del concejo murciano efectuadas entre 1450-1504, en 1491 «el concejo concede a Bartolomé de Brián 4 pares de tierra en el Charco del Prisco (Campo de la Matanza), que lindan con la Rambla de Santomera y la vereda y paso de los ganados extremeños» (Molina, 1989). ${ }^{2}$ Así, es probable que ambas personas fuesen la misma, aunque esta es solo una propuesta interpretativa.

En lo que respecta al siglo XVI, existe una curiosa «Provisión real de Carlos $\mathrm{V}$ a las autoridades de Murcia en relación al pleito que sigue Bartolomé Brian, de color negro, por una parte, y Pedro Fajardo y Catalina Brian, por la otra, a causa de la libertad del primero», fechada en 1 de septiembre de $1553,{ }^{3}$ y en la que llama la atención la coincidencia del nombre citado, Bartolomé, esclavo de color, con el antedicho canónigo. Además, resulta llamativa la presencia en la misiva de Pedro Fajardo Chacón, adelantado mayor del Reino de Murcia y I marqués de Los Vélez. Con todo, se desconoce si Catalina Brian pudiera ser pariente de alguno de los referidos Brian, aunque se sabe que era la viuda de Juan Brian, como consta en el «Expediente de censo de Catalina Brian [...] a favor del Fisco de la Inquisición de Murcia» del año $1564 .{ }^{4}$ Sin embargo, es igualmente desconocido quién era el referido marido de la citada Catalina. A todo esto se debe sumar el fehaciente conocimiento de la presencia en Murcia del notario Salvador Fernández de Brian, cuyo registro notarial de los años 1592 al 1595 y 1597 se encuentra entre la documentación custodiada por el Archivo General de la Región de Murcia (AGRM). ${ }^{5}$

De este modo, es evidente que el apellido Brian estaba presente entre los ciudadanos murcianos de esa época, lo que posibilita que alguno de ellos comprase o heredase las tierras que posteriormente serían conocidas con tal nombre en el Partido de Corvera.

1 Llamado realmente Bartolomé de Bricia, según Rodríguez y García (1994).

2 Archivo Municipal de Murcia (AMM), AC. 149-149, fol. 16 r.

3 AGRM. Not, 86, fol. 469v.

4 AGRM. Hacienda, 4007/193.

5 AGRM. NOT, 201; NOT, 202; NOT, 203; NOT, 204; NOT, 205 y NOT, 207. 
Tras un amplio vacío documental, en el siglo XIX Pedro Díaz Cassou, en un intento de presentar los orígenes del linaje Brian, en El Diario de Murcia del 4 de mayo de 1887 señaló que «hubo de este apellido una familia murciana, que no fue de las pobladoras, y que tuvo enterramiento en la Catedral». ${ }^{6}$ Un año más tarde, en este mismo diario, el 13 de mayo de 1888 en respuesta a la pregunta «si los Brianes que dieron nombre a un parage del campo de Murcia son de la familia del actual Iltmo. Señor Obispo», este mismo erudito contestó que «a fines del siglo XVI y durante todo el siglo XVII, encuentro en Murcia Brianes que tienen cargos de ciudad y dan nombre a una hacienda: Bryanes, que tal creo es el apellido del Sr. Obispo, no hubo en Murcia o yo no di con ellos». ${ }^{7}$ Afirmación que sostuvo el 5 de febrero de 1896 cuando en su columna añadió «Saluzio, familia de industriales acomodados y modestos terratenientes que dieron su nombre a un parage de nuestro campo, como lo dieron a otros, los Escobedos, los Brianes, los Garres, Lax, etc.». ${ }^{8}$ El citado obispo es Tomás Bryan y Livermore, quien ejerció el honorable cargo religioso en Murcia entre 1884 y 1902, año en el que falleció, realizándose en El Diario de Murcia una profusa descripción de su funeral en la Catedral de Murcia el 14 de septiembre. ${ }^{9}$

En este sentido, se sabe con exactitud que en 1869 ya existió en el paraje indicado una propiedad conocida como Hacienda de Los Brianes, puesto que en este año una finca situada en este emplazamiento y con igual nombre pertenecía a Nicolás Dato Rosique. Propiedad, muy posiblemente, heredada de su padre, debido a que próxima a esta existía otra en propiedad de la «señora viuda de Dato». ${ }^{10}$ Cabe señalar que Tomás Bryan no fue designado Obispo de Cartagena hasta 1885 (cargo que mantuvo hasta 1902), dieciséis años después de la antedicha referencia a la hacienda, por lo que surgen numerosas dudas acerca de sí fue posible que adquiriese la propiedad de la finca antes de 1869 o incluso que sus antepasados ya fuesen poseedores de esta, puesto que, conociendo que existieron vecinos de Murcia apellidados Brian, es difícil adjudicar una adaptación del apellido anglosajón Bryan por Brian. Un hecho no probado, además de que la interrelación entre ambos personajes, Tomás Bryan y Nicolás Dato, y la posibilidad de que su patronímico diese nombre al paraje citado, no está demostrada.

De esta forma, pese a los esfuerzos, no ha sido posible identificar la procedencia del antropónimo Brian aplicado al caserío de Los Brianes. La pista más cercana es la antedicha mención que hace Cassou en referencia a que a finales

\footnotetext{
El Diario de Murcia (04/05/1887), núm. 2990, p. 1. AMM, Hemeroteca

El Diario de Murcia (13/05/1888), p. 2. AMM, Hemeroteca.

El Diario de Murcia (05/02/1896), p. 2. AMM, Hemeroteca

El Diario de Murcia. 14/09/1902, p. 2. AMM, Hemeroteca.

10 Boletín Oficial de la Provincia de Murcia (BOPM), núm. 15, 19/07/1881. p. 1. AMM, Hemeroteca.
} 
del siglo XVI y durante todo el siglo XVII se encontraban en Murcia Brianes que ocupaban cargos notables en la ciudad y daban nombre a una hacienda. Paraje que, según se ha podido comprobar, vivió su máximo esplendor en época decimonónica, coincidiendo con la realización del Nomenclátor de 1888 y según el cual vivían en este «unos 30 vecinos, distribuidos en once edificios de un piso y uno de dos alturas» (IGE, 1892-1895). Hoy día, este caserío es un conjunto de viviendas en ruinas casi en su totalidad, a excepción de unas cuantas que han sido remodeladas recientemente, al tiempo que se produjo una profunda readecuación de la finca y el cauce de la Rambla de la Fuente del Alacrán, ahora llamada Rambla del Escobedo según el Mapa Topográfico Nacional.

\section{PROPIEDAD Y USO DE LA FUENTE DEL ALACRÁN}

La escasa información documental existente acerca de este manantial, prácticamente se limita al Expediente instruido sobre el aprovechamiento de las aguas de la Fuente del Alacrán situada en el Partido de Corvera, ${ }^{11}$ confeccionado en 1869 por el Gobierno Civil de la Provincia de Murcia. El referido documento puede dividirse en seis escritos, al margen de las formalidades de registro de entrada y salida, que permiten establecer una cronología de los hechos referentes a la disputa sobre el uso y propiedad del citado recurso hídrico:

1. Comunicación formulada por Nicolás Dato Rosique el 27 de febrero de 1869 ante la intención de los vecinos del Partido de Corvera de elevar una queja formal al Gobierno Civil de la Provincia por la supuesta apropiación y privación del derecho de uso común de la Fuente del Alacrán hecha por el referido hacendado.

2. Escrito de los vecinos del Partido de Corvera, con fecha del 9 de marzo de 1869, dirigido al Gobernador Civil en el que informan de la usurpación del derecho de uso común de la Fuente del Alacrán hecha por el indicado terrateniente.

3. Instancia de los alcaldes pedáneos de Corvera sobre el conflicto antedicho, con fecha de 18 de marzo, realizada a petición de la alcaldía de Murcia del día 16 de marzo.

4. Informe de la Comisión de Policía Rural sobre el asunto, fecha del 17 de junio, elaborado a petición de la alcaldía de Murcia el 21 de mayo y en la que se da la razón a los vecinos.

11 AMM. Legajo 1122. Cuaderno 1 (aguas). Expediente instruido sobre el aprovechamiento de las aguas de la Fuente del Alacrán situada en el Partido de Corvera. 
5. Comunicación de los alcaldes pedáneos de Corvera, fecha de 28 de junio, dirigida a la alcaldía de Murcia y en la que informan de la negativa de los trabajadores de Nicolás Dato Rosique de destapar la fuente para restablecer su aprovechamiento común ante la exigencia impuesta por la corporación municipal.

6. Nota de los alcaldes pedáneos de Corvera, con fecha 29 de junio de 1869 , en la que se comunica al alcalde de Murcia la consecución del destape de la fuente y su puesta de nuevo en uso público.

Sin duda, la existencia de este expediente es determinante para el estudio del presente trabajo ya que, entre la información aportada en el citado documento, existen diversas alusiones al origen de la Fuente del Alacrán, la propiedad de la misma y las distintas obras realizadas por Nicolás Dato Rosique para su encauzamiento. Cuestiones, todas ellas, de enorme importancia a la hora de abordar el análisis histórico y arquitectónico de la obra hidráulica.

En lo que se refiere al primer asunto, en la instancia elevada por los vecinos del Partido de Corvera al Gobierno Civil el 9 de marzo de 1869, estos señalan:

\footnotetext{
«Que en dicho Partido existe una fuente llamada del Alacrán, situada en una Rambla a que da nombre dicha fuente, la cual ha servido desde los tiempos mas remotos como abrevadero para los ganados, y de ella se han surtido todos los vecinos y moradores de la comarca, para apagar la sed en tiempos estériles ó de sequia».
}

Además, en el comunicado de Nicolás Dato Rosique del 27 de febrero de 1869, este dice:

\begin{abstract}
«Conste ante todo, que la Rambla en que practiqué el alumbramiento de agua, en cuestión, toda ella plantada de arbolado, cuatro años antes, se llama por tradición "De la fuente del Alacrán" y que si bien es verdad que en un sitio de ella (por cierto fuera de mi propiedad) existió un resudador que dieron en llamarle Fuente, también lo es, que hace mas de cuarenta años que fue abandonado por haber desaparecido del terreno sin el menor vestigio de agua».
\end{abstract}

En el informe de la Comisión de la Policía Rural fechado en 17 de junio de 1869, se expone que existe una información, ad perpetuam, de tres testigos realizada a citación del Procurador Fiscal del Distrito de la Catedral -se supone a petición de Nicolás Dato Rosique- presentada por el referido hacendado y que dice:

«Dho Rosique es dueño de una hacienda llamada los Brianes, formando parte de ella un trozo de rambla plantada de arboles, en cuyo centro existía un resudador o manantial conocido siempre con el nombre del Tío Mochuelo, por llamarse así el que lo abrió y 
utilizó primero para su servicio particular: que hace once años condujo las aguas susodichas por su propiedad a otro punto de la mina, donde era más conveniente su aprovechamiento».

Más tarde, el 4 de agosto de 1869, se publica en el Boletín Oficial de la Provincia de Murcia, que el día 11 de junio «también se acordó en vista de expediente instruido á instancia de los vecinos del partido de Corvera y de conformidad con lo informado por la Comisión de policía rural, que los recurrentes pueden utilizar en la forma que lo han verificarlo siempre las aguas de la fuente titulada del Alacrán, como de aprovechamiento común». ${ }^{12}$

En base a estas tres referencias (sin contar la del 4 de agosto de 1869), se tiene constancia de un aprovechamiento histórico de las aguas. Si bien, la locución adverbial «desde tiempos remotos» no permite establecer un marco temporal concreto y definido, desconociéndose, por tanto, desde cuándo se utiliza el referido recurso, aunque, atendiendo al contexto del escrito, parece que se hace alusión a una época anterior a las obras de alumbramiento realizadas por Nicolás Dato Rosique. En este sentido, es probable que los apuntes de los vecinos se retrotraigan a las aguas que manaban del resudador o manantial abierto por el Tío Mochuelo en un momento desconocido y cuya existencia citan tanto el indicado hacendado en su escrito, como los tres testigos de la información dada ante el Procurador Fiscal.

Con todo, teniendo en cuenta el origen incierto de la labor realizada por el referido Tío Mochuelo, según lo manifestado por el propietario de la Hacienda de Los Brianes, se sabe que este punto de abastecimiento fue abandonado antes de 1829 con motivo de su disfuncionalidad, bien por agotamiento del recurso o bien por un descenso de los niveles freáticos.

En esta situación, y ante el conocimiento de la riqueza hídrica de la Rambla de la Fuente del Alacrán, según lo apuntado por los tres testigos, Nicolás Dato alumbró las aguas que circulaban por el subsuelo del cauce en 1858 y las condujo, por medio de un caño de obra, hasta las tierras de su propiedad con la intención de ponerlas en riego. De esta forma, atendiendo a lo expuesto y confiando en que sean testimonios verídicos en todos los casos, debieron existir dos puntos de explotación de los recursos ocultos de la rambla: por un lado, desde un momento indeterminado hasta, aproximadamente, el primer tercio del siglo XIX, el primigenio resudador acondicionado por el señalado Tío Mochuelo, obra de la que poco se conoce y a la que los vecinos ya atendían a llamar fuente; por otro, el caño y mina construido a mitad del citado siglo por el referido hacendado murciano.

12 El Diario de Murcia (04/08/1869), p. 3. AMM, Hemeroteca. 
En lo que se refiere a la propiedad de las aguas, como queda dicho, el señor Dato Rosique expone en su comunicación que el resudador conocido como Fuente del Alacrán, cuyo disfrute podía ser de uso común desde tiempo inmemorial y cuya ubicación quedaba fuera de sus propiedades, quedó abandonado debido a la desaparición de los caudales que de él brotaban. Por este motivo, tiempo después, él mismo decidió realizar, por su cuenta, una nueva captación mediante mina y caño en otro punto distinto de la misma rambla, lugar que sí se encontraba ubicado dentro de su propiedad, razón por la cual se consideraba dueño de estas aguas de las que, en ocasiones y por caridad, como él mismo señala, dejó que se abastecieran los vecinos de forma gratuita o mediante el pago de un canon cuando la aglomeración de estos dañaba la propia conducción y mermaba los recursos disponibles.

No obstante, obviando ambas consideraciones, si se tiene en cuenta que fue en 1858 cuando se alumbraron nuevamente las referidas aguas, cabe decir que en aquel momento la legislación vigente era la Real Orden de 21 de agosto de 184913 (posterior a la Real Orden de 14 de marzo de 1846), según la cual solo serían aguas privadas las alumbradas en propiedades particulares (Pérez, 1992). De este modo, si el propietario de la Hacienda de Los Brianes estaba en lo cierto al afirmar que sus obras se habían ejecutado en terrenos de su propiedad, las aguas alumbradas le pertenecían, sin estar en obligación alguna de poner en uso común gratuito este recurso; todo lo contrario, si se entiende que los terrenos donde se obró el caño y la mina eran de dominio público.

Teniendo en cuenta el contenido del precitado expediente, en el escrito de los vecinos de Corvera dirigido al Gobierno Civil el día 9 de marzo de 1869, estos dejan claro que la citada fuente era utilizada, desde tiempos remotos, para el abasto de la ganadería y el consumo humano. Realizadas las primeras obras por Nicolás Dato, las aguas captadas eran de uso popular, mientras que los sobrantes fueron dedicados por el hacendado al cultivo de su extensa propiedad, privilegio que fue privatizando paulatinamente hasta el punto de cobrar «16 maravedís por cada carga de agua de cuatro cántaros» ${ }^{14}$ en un territorio donde el agua, en los episodios de mayor sequía, obligó a emigrar a sus pobladores a provincias con mayor disponibilidad de recursos hídricos. Incluso llegó a negar el aprovechamiento total de este manantial debido, según él mismo expone, al impacto sufrido por el abusivo uso que hacían de él los propios vecinos de Corvera.

13 Real Orden circular aclarando las dudas que puedan ocurrir sobre cumplimiento de la Real Orden de 14 de Marzo de 1846, relativa al aprovechamiento privado de aguas corrientes. Gaceta de Madrid, núm. 5458, 23/08/1849, p. 1. Ministerio de Comercio, Instrucción y Obras Públicas.

14 AMM. Legajo 1122. Cuaderno 1 (aguas). Expediente... 
Una vez ejecutadas las obras de captación y canalización, «no pasó mucho tiempo sin ver aglomerarse gentes, hasta de largas distancias», lo cual provocó que los arrendatarios de la finca se viesen perjudicados ante la escasez de agua útil, por lo que, además de imponer un arbitrio para el aprovisionamiento antes citado, el señor Dato afirma:

\begin{abstract}
«Animado siempre del deseo de hacer bien al público, abro un pozo de agua potable en la misma Rambla para que se surtieran de ella, ó cuando menos que llenasen en él, para vaciarla en la balsa de riego, sustituyendo de este modo la que estrajeran del caño. No paró aquí mi bondad, sino que para hacerlo menos costoso les pongo garrucha, pila y pilón; y mi labrador las correspondientes sogas: pero nada es suficiente; tanta bondad la interpretan como una obligación, y solo teniendo de continuo tres ó cuatro vigías cumplían con lo prevenido; y últimamente, buscando un pretesto para no llenar, ó cortaban la soga, ó se la llevaban fraudulentamente; visto tanto descaro, y tanta ingratitud, me he visto obligado a embovedar por segunda vez el Caño y abrevador, con la prohibición espresa de que no se estraiga por nadie, ni por nada, una sola gota del agua que debe caer á la balsa». ${ }^{15}$
\end{abstract}

Con todo, la Alcaldía de Murcia, consultados los escritos de los vecinos, los de los alcaldes pedáneos y los del propio Nicolás Dato Rosique, finalmente ordena a los pedáneos de Corvera que obliguen a los encargados de la Hacienda de Los Brianes a destapar el caño de la Fuente del Alacrán para que los vecinos pudieran abastecerse libremente de ella. Objetivo que, tras varios intentos, se logró alcanzar el 29 de junio de 1869, comunicando los referidos pedáneos la noticia al alcalde de Murcia del siguiente modo:

«Que por la benéfica disposición del Sr. Alcalde popular, como órgano y presidente del muy Excmo. Ayuntamiento de la Capital, quedaba espuesta para el servicio del publico las citadas aguas de la Fuente del Alacrán, prorrumpiendo en alegres demostraciones los muchos espectadores celebrando tan fausto acontecimiento con mil géneros de alegres demostraciones que dieron hasta la caída de la tarde». ${ }^{16}$

\title{
5. NICOLÁS DATO ROSIQUE
}

Como queda dicho, en 1858 Nicolás Dato Rosique, propietario entonces de la Hacienda de Los Brianes, es el ejecutor de la obra de captación y canalización más reciente realizada en la rambla de la Fuente del Alacrán. Por este motivo, se ofrece, a continuación, una síntesis de la vida de este terrateniente como herramienta de aproximación a las características y motivaciones de los propietarios que emprendían obras hidráulicas para el aprovisionamiento de sus haciendas.

15 AMM. Legajo 1122. Cuaderno 1 (aguas). Expediente...

16 Ibidem. 
Según las noticias de prensa de la época, fue un notario ${ }^{17}$ y médico residente en Murcia que aparece en la lista de los electores a Diputados a Cortes constituyentes del Reino por la Parroquia de San Andrés de esta ciudad en los años 1854, 1858, 1863, 1864 y $1866 .{ }^{18}$ Más tarde, en el mismo año en que sucede el conflicto por la propiedad de las aguas de la Fuente del Alacrán (1869), es citado en el BOPM del día 30 de marzo como «Contribuyente de $2^{\text {a }}$ categoría»-con un total de 52.735 escudos- designado, junto a otros 83 contribuyentes ( 24 de cada categoría: $1^{\mathrm{a}}, 2^{\mathrm{a}}$ y $3^{\mathrm{a}}$ ), para discutir el presupuesto municipal. ${ }^{19}$ Esta circunstancia refleja su posición dentro de la sociedad murciana de la época, además de tratarse de una suma de dinero bastante elevada con respecto al resto de contribuyentes de su categoría, hecho que lo sitúa entre las personas con mayor número de escudos en este rango, aunque lejos de aquellos que ocupaban el primer escaño de la clasificación.

Algunos años después, con motivo de la llegada al trono de Alfonso XII y como componente de las Juntas Católico Monárquicas de Murcia, jura, junto a Mariano Díaz Puche, como particular de Murcia y ante el Gobernador Civil de la Provincia, sumisión y reconocimiento al nuevo rey, como así lo publica el BOPM del día 21 de julio de $1875 .{ }^{20}$ Casi un año más tarde, el 19 de julio de 1881 se publica en este mismo boletín un anuncio del Gobernador Civil de la Provincia de Murcia en el que dice:

«D. Joaquín Helguero Uriarte, Gobernador civil de esta provincia. Hago saber: Que por D. Demetrio Roveda Molerá, vecino de esta ciudad, se ha presentado en este Gobierno de provincia una instancia fecha 25 de Junio último, solicitando se le concedan setenta y dos pertenencias para la mina denominada «El Diluvio», de mineral de hierro y otros, sita en término de esta capital, y en terrenos montuosos y parte laborizable, hacienda llamada de los Señoritos, de la propiedad de la señora viuda de Dato, diputación de Baños y Mendigo y Corvera; lindando por N. hacienda llamada Las Llanas; S. viuda de Dato; E. viuda de D. Benito Malvasía, y O. hacienda llamada Los Brianes, de la propiedad de D. Nicolás Dato Rosique cuyo registro le ha sido admitido por decreto de este día, salvo mejor derecho bajo la siguiente designación: Se tendrá por punto de partida la fuente del barranco del Alacrán». 21

17 El Diario de Murcia. 03/02/1880, p. 2. AMM, Hemeroteca.

18 Boletín Oficial de la Provincia de Murcia, núm. 144, 02/10/1854. pp. 7-8; núm. 128, 07/08/1858. p. 1; núm. 196, 23/11/1863. p. 5; núm. 23, 02/08/1864. p. 1; núm. 236, 24/11/1864. p. 1; y núm. 283, 28/11/1868. p. 1. AMM, Hemeroteca.

19 Boletín Oficial de la Provincia de Murcia, núm. 74, 30/03/1869. p. 4. AMM, Hemeroteca.

20 Boletín Oficial de la Provincia de Murcia, núm. 18, 21/07/1875. p. 1-2. AMM, Hemeroteca.

21 Boletín Oficial de la Provincia de Murcia, núm. 15, 19/07/1881. p. 1. AMM, Hemeroteca. 
En esta línea de solicitud de concesiones mineras, se registran varios anuncios que permiten conocer la existencia de varias de estas explotaciones en terrenos de la Hacienda de Los Brianes, lo que refleja la gran extensión de la misma, en la que se incluían tierras montuosas de las faldas de Carrascoy donde se desarrollaban las indicadas actividades extractivas. En este sentido, el 14 de agosto de 1881, en el BOPM (anuncio 4.091 de la sección de Fomento, Minas), se dice:

\begin{abstract}
«Hago saber: Que por D. Anselmo Sandoval y Braco, vecino de esta ciudad, se ha presentado en este Gobierno de provincia una instancia fecha 19 de julio último, solicitando se le concedan diez y seis pertenencias para la mina denominada San «Buenaventura», de mineral de hierro y otros, sita en término de esta capital y en terreno de la propiedad de la viuda de Dato Rosique, paraje que llaman Barranco de la Fuente del Alacrán, diputación de Corvera; lindando por el N. con propiedad de D. Vicente Pareja; L. hacienda de la viuda de D. Benito Malvasía; M. con la viuda de Dato, y P. con la hacienda de D. Nicolás Dato Rosique». 22
\end{abstract}

Poco después, el 1 de septiembre de 1881, se publica un anuncio similar (número 4.192) donde se señala que Francisco Jódar Serrano, vecino de la ciudad de Murcia, solicita que «se le concedan veinte y cuatro pertenencias» de a una mina titulada El Baluarte, situada en terrenos de la hacienda de Nicolás Dato Rosique en Corvera. ${ }^{23}$

Más tarde, en 1885 es sustituido por Pedro Guirao Martínez en su labor de Notario eclesiástico y oficial mayor de la Notaria del Tribunal Eclesiástico del Obispado, según el nombramiento expedido por el Obispo el 24 de marzo y recogido en el diario La Paz de Murcia el 5 de abril. ${ }^{24}$ En ese mismo año, en El Diario de Murcia del 28 de junio se anuncia que acepta asistir gratuitamente como médico a los enfermos de cólera de Corvera ante la oferta de Provisor del Obispado, «lo cual honra sobremanera al Sr. Rosique», 25 y deja entrever que, a pesar de los enfrentamientos con los vecinos de la localidad por la explotación del manantial, este se mostró solidario con ellos en una situación tan grave.

Algunos años más tarde, concretamente en 1889, aparece citado como una de las personas notables que asistieron a la fiesta organizada en el Templo de San Andrés con motivo del «XIII centenario del memorable acontecimiento de la Conversión de Recaredo y consagración de España a la unidad católica», ${ }^{26}$ mientras que el día 26 del mismo mes se publica en La Enseñanza Católica, que con-

22 Boletín Oficial de la Provincia de Murcia, núm. 38, 14/08/1881. p. 2. AMM, Hemeroteca.

23 Boletín Oficial de la Provincia de Murcia, núm. 53, 01/09/1881. p. 3. AMM, Hemeroteca.

24 La Paz de Murcia. 05/04/1885, p. 1. AMM, Hemeroteca.

25 El Diario de Murcia. 28/06/1885, p. 2. AMM, Hemeroteca.

26 El Diario de Murcia. 09/05/1885, p. 2. AMM, Hemeroteca. 
tribuyó con 1 peseta y 50 céntimos para la instalación de una placa conmemorativa de tal acontecimiento. ${ }^{27}$ En ese mismo año, el 2 de junio, aparece una suscripción de 8 reales hecha en favor de Agustín González Ximenez, ${ }^{28}$ director de la parte gráfica de la revista ilustrada La Camelia, periódico quincenal, literario y de dibujos que se comenzó a imprimir en 1880 (Alcaraz, 1996).

Por último, el día 12 de agosto de 1890 Nicolás Dato Rosique recibe la extremaunción, ${ }^{29}$ aunque no falleció hasta tiempo después, ${ }^{30}$ siendo enterrado el día 26 de septiembre en un acto presidido por «el Sr. Provisor D. Gabriel Mallo, el párroco de San Andrés, el Sr. Alcalde, D. José Esteve y D. Juan de la Cierva. Llevando las cintas del féretro D. Miguel Gasque, D. Narciso Clemencín, D. Emilio López Guillén y D. Lorenzo Pausa». ${ }^{31}$

\section{ANÁLISIS ESTRUCTURAL DE LA MINA Y CONDUCCIÓN}

Como se ha comentado con anterioridad, parece ser que han existido dos captaciones independientes, nombradas igualmente como Fuente del Alacrán. Por un lado, el resudador o manantial excavado por el Tío Mochuelo y, por otro, la mina y caño construidos por Nicolás Dato Rosique a mediados del XIX. En lo que se refiere a la primera, no se dispone de datos que permitan una descripción fiel de la actuación llevada a cabo para el aprovechamiento de los caudales de la citada surgencia, si bien, sabemos que fue la persona indicada la primera documentada que llevó a cabo alguna acción para disfrutar de este recurso. Por lo que respecta al segundo caso, se sabe que en 1858, aproximadamente, Nicolás Dato practicó las acciones oportunas para alumbrar las aguas del subálveo mediante una obra que su propio dueño calificó como de «innovación de [...] comodidad y limpieza» ${ }^{32}$ y cuya efectividad está más que probada, como se deduce de su apreciado uso tanto por su propietario como por los vecinos de Corvera y aquellos que se abastecían, igualmente, en este punto.

De este modo, y en base al trabajo de campo, el sistema de la Fuente del Alacrán construido en el siglo XIX -hoy en día seco, en desuso y deteriorado, aunque conservado en parte- se compone de tres elementos diferenciados que son habituales en esta tipología de captaciones en medios semiáridos: mina de agua, acequia y balsa.

27 La Enseñanza Católica. 26/05/1889, p. 1. AMM, Hemeroteca.

28 El Diario de Murcia. 02/06/1889, p. 3. AMM, Hemeroteca.

29 El Diario de Murcia. 12/08/1890, p. 2. AMM, Hemeroteca.

30 El Diario de Murcia. 24/09/1892, p. 1. AMM, Hemeroteca.

31 El Diario de Murcia. 27/09/1890, p. 3. AMM, Hemeroteca.

32 AMM. Legajo 1122. Cuaderno 1 (aguas). Expediente... 
Figura 2. Detalle de la entrada a la mina de agua.

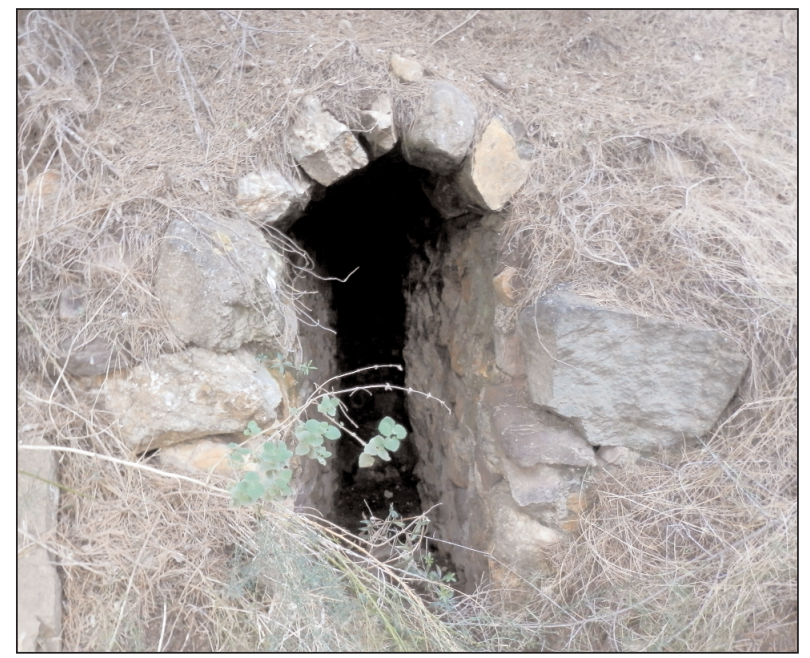

\section{a) Mina de agua}

La obra está conformada por una galería de $90 \mathrm{~m}$ de longitud, de ápice en bóveda de cañón, sin lumbreras o registros, excavada en el lecho de la Rambla del Escobedo -o Rambla de la Fuente del Alacrán- y en la que desde la bocamina (X: 660199, Y: 4193720) (Figura 2) hasta unos $5 \mathrm{~m}$ hacia el interior, sus paredes presentan un refuerzo mediante obra de mampostería de fragmentos de roca del entorno, ligados con argamasa.

La estructura se conserva en buen estado, mientras que morfológicamente no difiere mucho de otras galerías construidas en los siglos XVIII y XIX en el Campo de Cartagena. No obstante, en este caso, la construcción carece de canalillo o andenes por los que transitar evitando mojarse los pies durante las tareas de reconocimiento y mantenimiento de la misma, característica que sí está presente, por ejemplo, en el sistema localizado en La Pinilla, propiedad de Francisco Vivancos en el siglo XIX (Castejón, 2014). Pese a todo, esta no resulta ser una cualidad muy presente en los demás sistemas analizados en los diferentes trabajos citados con anterioridad, ya sea por su mayor complejidad, por el incremento en el coste de su realización o simplemente porque no era una cuestión que preocupase a sus propietarios.

En su interior (Figura 3) la mina, excavada por entero en el terreno, posee una luz de $50 \mathrm{~cm}$ de ancho y 1'60 $\mathrm{m}$ de alto, dibujando en la parte superior un arco de unos $50 \mathrm{~cm}$ de ancho por $30 \mathrm{~cm}$ de alto. Igualmente, cabe decir que en la parte final de la galería, las medidas, tanto de anchura como de altura, van reduciéndo- 


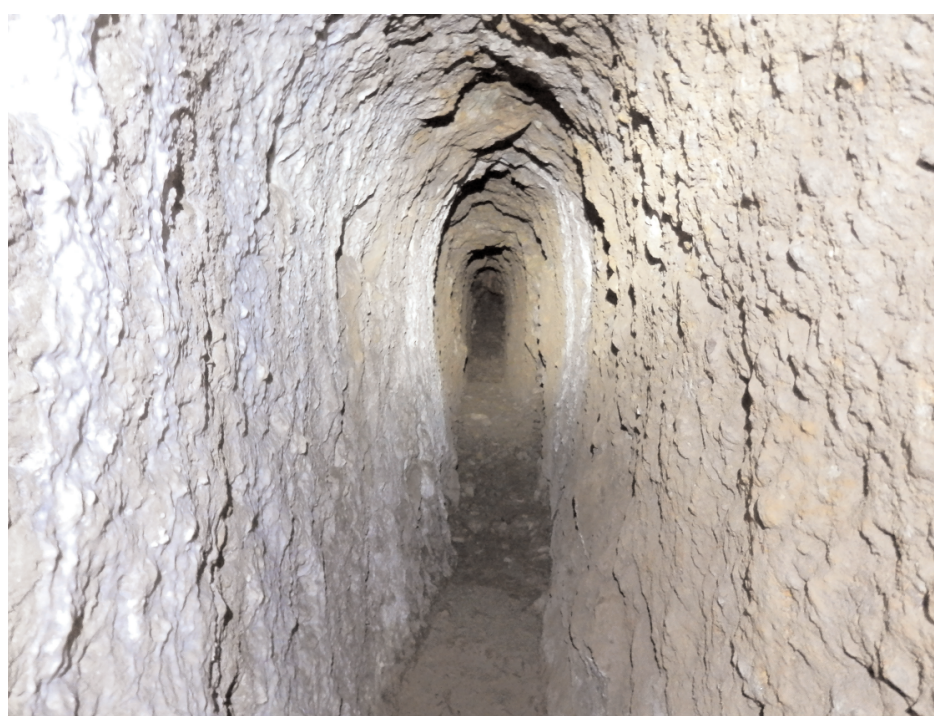

Figura 3. Interior de la mina de agua.

se a razón de la cercanía al arranque de la misma. En este punto inicial, no se aprecia ningún tipo de receptáculo de acumulación de agua, simplemente la pared desnuda picada en la búsqueda de los veneros de los que debía brotar el agua. Además, no se ha encontrado en su interior ningún tipo de estructura relevante, a excepción de la propia mina que se encuentra en buen estado de conservación, hasta el punto de ser posible su acceso hasta el origen de la misma.

\section{b) Acequia}

Traspasada la bocamina de la galería subterránea, el agua fue canalizada por medio de una acequia de algo más de un kilómetro, compuesta por piezas de arenisca labrada de unos $85 \mathrm{~cm}$ y 40'50 cm de largo, 12'50 cm de ancho y $12 \mathrm{~cm}$ de alto, trabadas mediante mortero hidráulico (Figuras 4 y 5). Esta solución es un recurso utilizado en diversas canalizaciones de esta tipología en la Región de Murcia, si bien la zona de Corvera, y fundamentalmente La Murta, tiene una amplia reputación de afamados canteros en la época de construcción de este sistema (Mas, 2012) por lo que, junto con la presencia extendida del material apropiado en las inmediaciones, no es de extrañar la aplicación de esta técnica en el caso de análisis, además de su efectividad y perdurabilidad en el tiempo si no sufre graves agresiones físicas por parte del ser humano, como ha ocurrido con gran parte de la canalización de la que apenas se conserva un 25\%. Asimismo, 


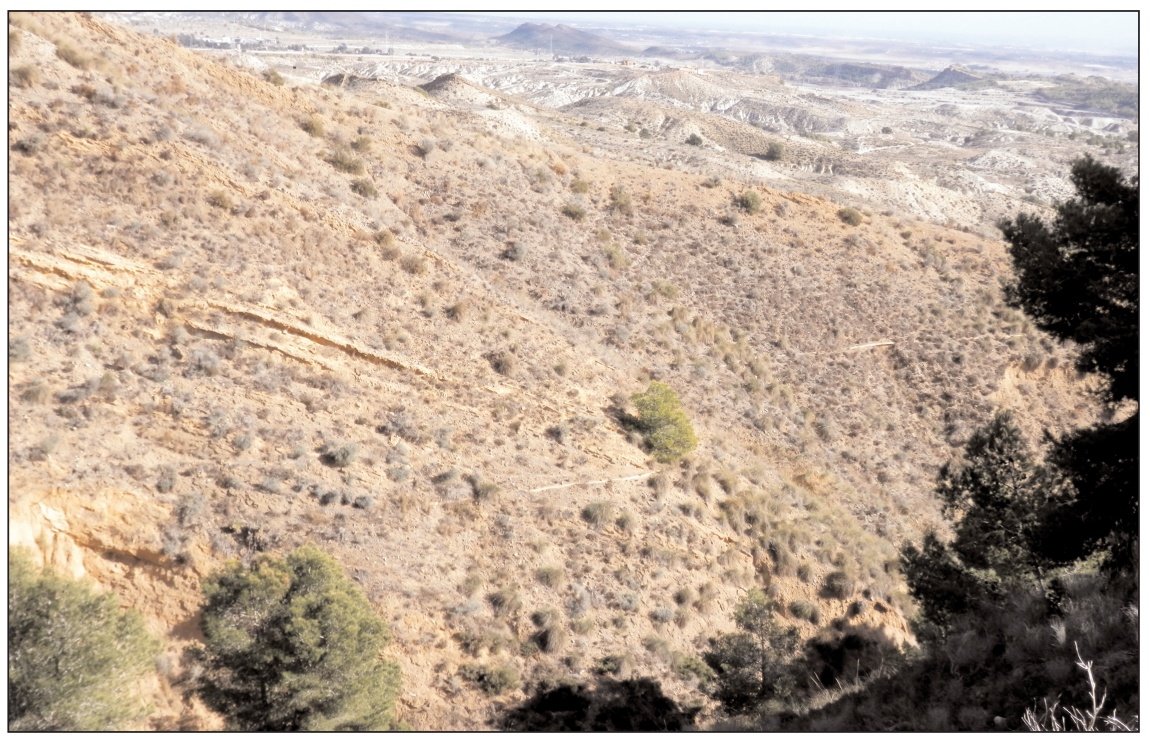

Figura 4. Tramos de la conducción todavía visibles en las inmediaciones de la rambla.

resulta importante señalar que para salvar los accidentes de la topografía por donde discurre la conducción, se confeccionaron dos acueductos de mampostería que otorgan un grado de belleza e ingenio todavía mayor a la estructura. El primero de ellos (X: 660315; Y: 4193655) tiene de 4'5 $\mathrm{m}$ de alto, $80 \mathrm{~cm}$ de ancho y unos 6'5 m de largo (Figura 6). El segundo (X: 660339; Y: 4193644), ubicado a

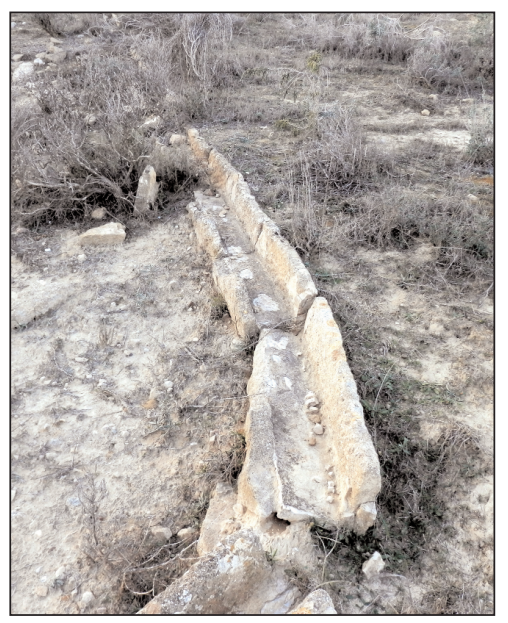

Figura 5. Tramo visible del caño. unos $30 \mathrm{~m}$ del anterior, es de unas dimensiones más reducidas aunque igualmente llamativo.

En todo caso, desde el inicio de la acequia, prácticamente en el lecho de la rambla de la Fuente del Alacrán, esta se va separando, progresivamente, del cauce hacia el este, manteniendo una leve pendiente descendente apenas perceptible pero constante. Después de algo más de $300 \mathrm{~m}$ de caño visible, se pierde su pista de forma repentina, quizás debido a las profundas roturaciones que sufrió el entorno en el siglo XX y a la construcción de un camino forestal, o, tal vez, fuese desmantelado para reutilizar 


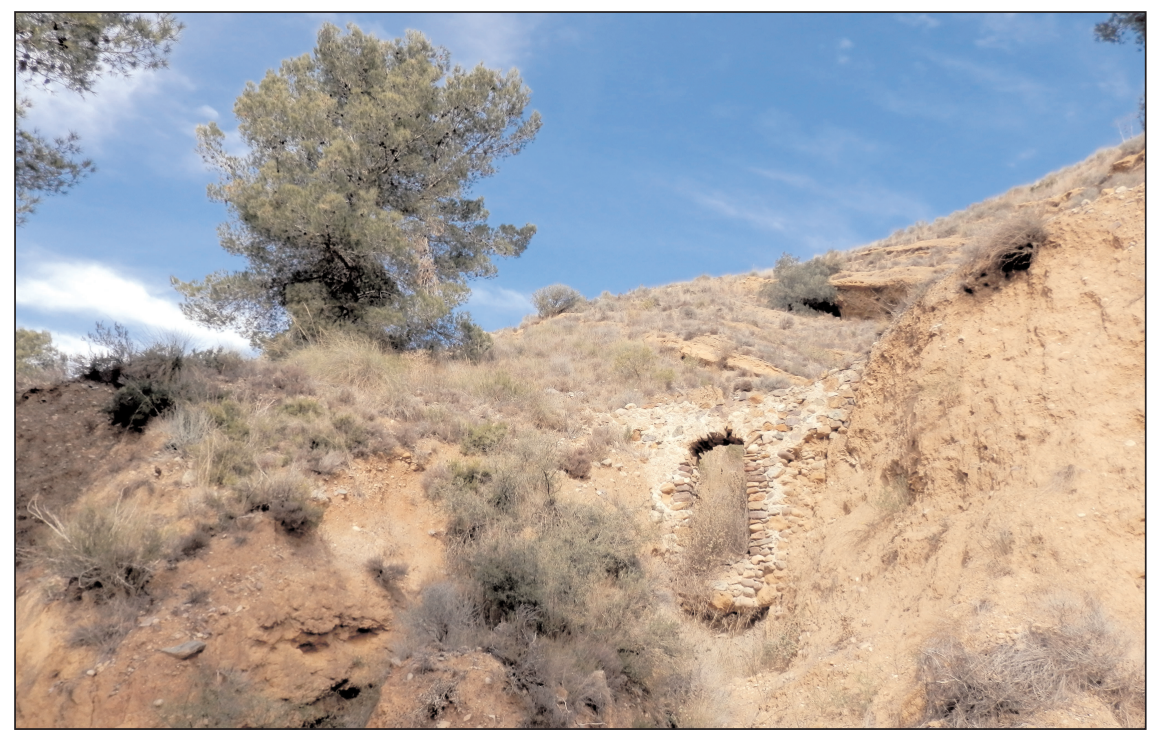

Figura 6. Uno de los dos acueductos de la canalización.

sus piezas de arenisca en otras obras hidráulicas posteriores después de haber quedado inservible. El hecho es que, desde este punto próximo al segundo acueducto hasta la balsa situada junto a la Casa de la Fuente, no se aprecia resto alguno del caño.

\section{c) Balsa}

Hay que ser cauto a la hora de abordar este apartado, pues en el entorno de Los Brianes existen cuatro balsas de acopio de agua, dos rectangulares y otras dos circulares, si bien la localización de la canalización en la margen izquierda de la rambla y la existencia de uno de estos depósitos junto a la Casa de la Fuente, confirman que sea esta la que formaría parte del conjunto de análisis. No obstante, físicamente y debido a la transformación del espacio, no existe una conexión visible entre ambos elementos, como se ha apuntado anteriormente.

Se trata pues de una balsa circular de unos $11 \mathrm{~m}$ de diámetro (Figura 7) cuya factura de la obra parece ser moderna, muy posiblemente por haber sufrido una reedificación reciente con la intención de aumentar el volumen acumulable posible.

Por contra, el resto de receptáculos forman parte de sistemas hidráulicos independientes de obtención de caudales. En el caso de los depósitos rectangulares, estos debían almacenar el agua captada de las escorrentías de las ramblas 


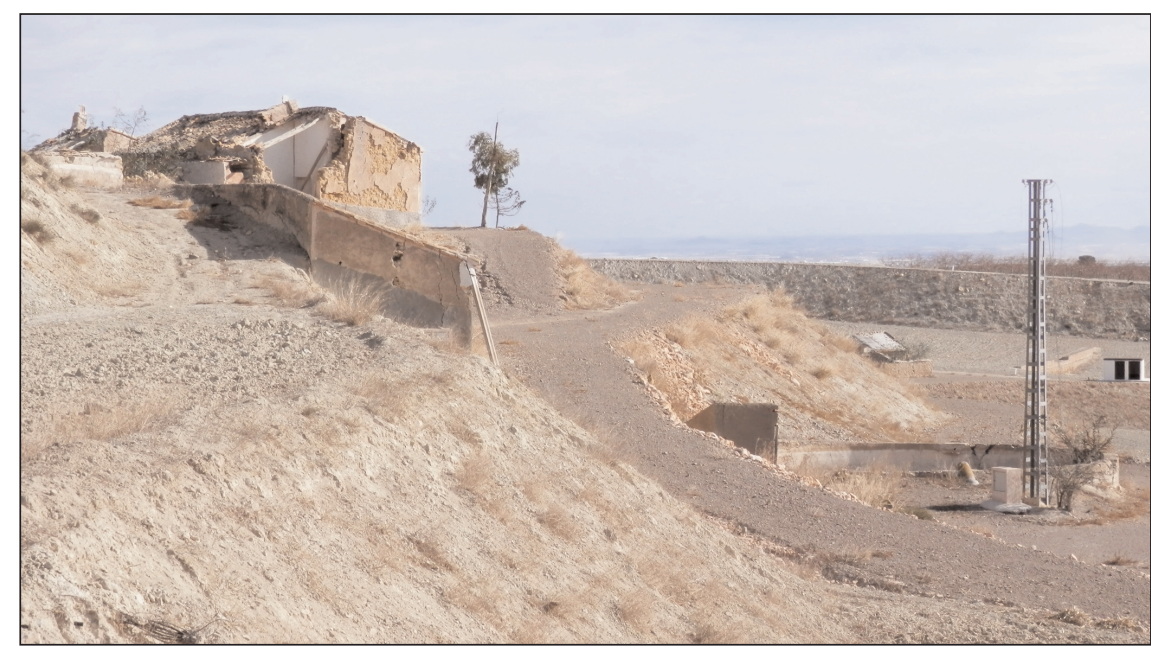

Figura 7. Casa de la Fuente y balsa.

paralelas situadas al oeste del cauce objeto de estudio o quizás, al igual que en el marco de análisis, el origen de las mismas sean sendas minas construidas en el lecho de sus cauces. Sin embargo, el acceso restringido a la finca no permite comprobar esta teoría aunque cabe decir que tampoco se conoce la existencia de otra fuente similar a la analizada en este documento en ninguna de las ramblas limítrofes. Ambas balsas presentan unas características comunes, pequeño tamaño y derramador de arenisca, que hacen pensar en un origen antiguo, quizás posibles reminiscencias de un aprovechamiento contemporáneo al primigenio dado en la rambla de la Fuente del Alacrán. Por último, la tercera balsa, de factura circular, por el contrario, es evidentemente una construcción mucho más reciente que las demás, siendo abastecida por un moderno pozo vertical motorizado.

\section{CAPTACIONES SECUNDARIAS}

Como se ha comentado, en esta misma Rambla del Escobedo y unos $650 \mathrm{~m}$ aguas abajo de la bocamina de la galería construida por Nicolás Dato Rosique, se hallan los restos de otras tres canalizaciones visiblemente distintas, cuyas diferencias tipológicas parecen estar motivadas por la época de construcción de las mismas.

Según se ha podido comprobar en el trabajo de campo, parece ser que los tres sistemas partían de una presa (X: 660464; Y: 4193270) de 3'20 m de ancho y 1'50 $\mathrm{m}$ de grosor en la parte superior y $2 \mathrm{~m}$ de ancho y 1'70 $\mathrm{m}$ grosor en la inferior, con lo que el agua represada por la obra debía ser introducida o derivada a las conducciones, algo que físicamente no se ha podido documentar debido al deterioro 


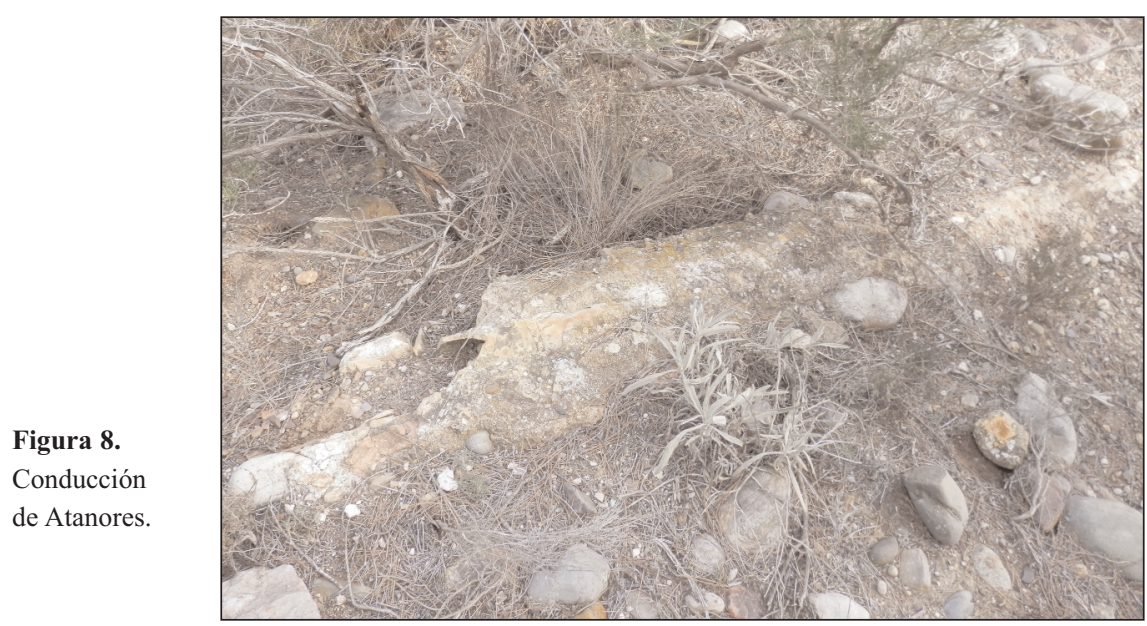

de los restos visibles. Cabe señalar, que para la edificación del referido represamiento, se aprovechó un estrechamiento de la rambla que permitía una mayor fortaleza de la obra, así como una complejidad menor en su ejecución.

Con todo, cada una de las tres conducciones indicadas presenta una tipología distinta:

\section{a) Conducción de atanores}

Está confeccionada mediante atanores cerámicos tubulares machihembrados, de más de $40 \mathrm{~cm}$ de longitud, $1 \mathrm{~cm}$ de grosor y $9 \mathrm{~cm}$ de diámetro aproximado (Figuras 8 y 9). Salvaguardando la estanqueidad y firmeza de la obra, esta se asienta sobre una capa de mortero, por lo general de grano medio con algunas piedras de tamaño considerable. Mortero que, igualmente, cubre la canalización aumentando con ello su perdurabilidad. Asimismo, entre atanor y atanor, se aprecia la utilización una pasta de unión que tendría como misión evitar las pérdidas del preciado líquido, además de dar solidez a la propia estructura. Pese a que esta solución técnica aplicada en obras hidráulicas está presente en el territorio nacional desde época romana hasta el siglo XX, lo cierto es que apenas existen paralelos regionales, hecho por el cual la cita de su presencia es de relevancia patrimonial.

\section{b) Conducción de doble teja}

Edificada mediante un conducto de unos $10 \mathrm{~cm}$ de diámetro fabricado mediante dos tejas de unos $30 \mathrm{~cm}$ de largo y $16 \mathrm{~cm}$ de ancho colocadas una sobre otra por su parte cóncava y con la parte más estrecha en el sentido contrario al 
de la corriente que circularía por la canalización (Figura 10). El grosor de cada una de estas tejas es de $2 \mathrm{~cm}$ en su centro y 1'5 $\mathrm{cm}$ en los bordes, recubiertas ambas con mortero de cal y arena para proteger y asegurar la estanqueidad de la conducción, así como para dar firmeza a la base y estructura de la misma. Mortero que, al contrario que en el primer caso, parece ser de un grano algo

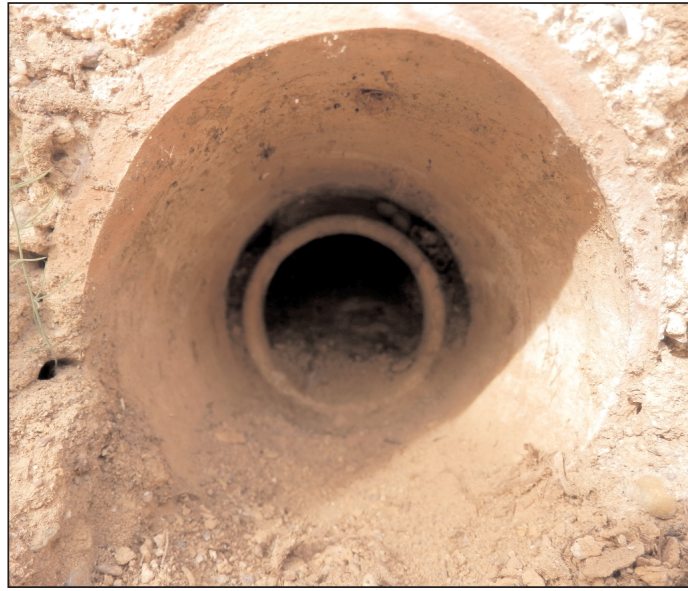

Figura 9. Vista en detalle de los atanores. más fino, aunque también se encuentran incrustadas en este, grandes piedras y fragmentos de teja.

Sin que sirva de elemento de datación pero sí de comparación, una obra hidráulica de factura similar la encontramos a nivel regional en el caño de la Fuente de la Gota en Mula, canalización edificada a mediados del siglo XVIII a petición de las Religiosas Clarisas del Real Monasterio de la Encarnación de esa ciudad según la información aportada por López y Gómez (2008).

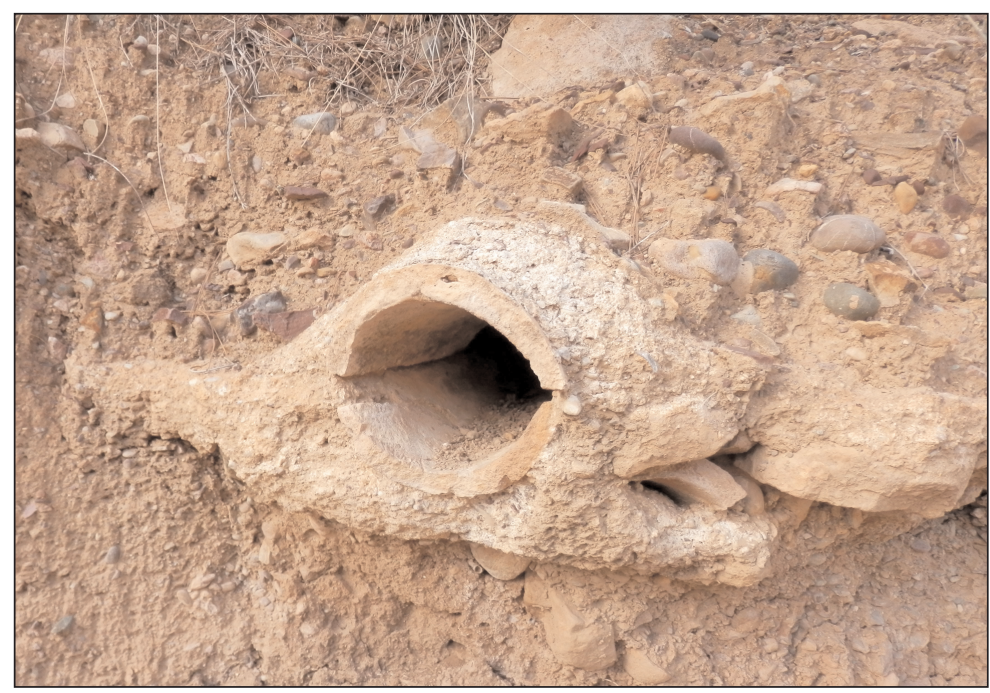

Figura 10. Conducción de doble teja. 


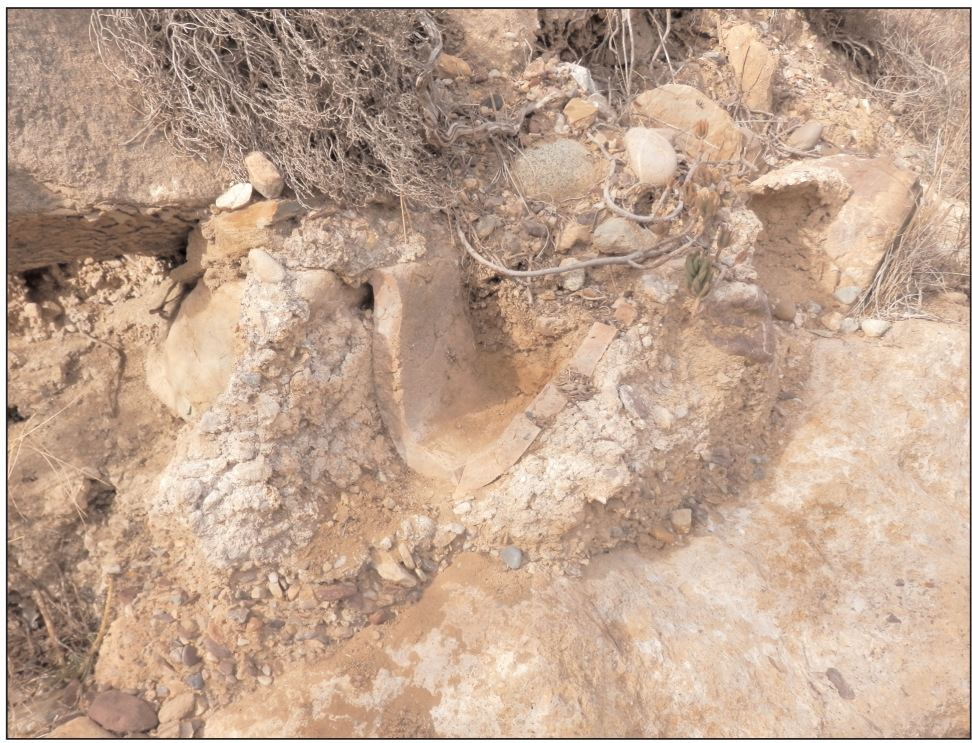

Figura 11. Conducción de piezas cerámicas de sección aguda.

\section{c) Conducción de piezas de cerámica de sección aguda}

Canalización construida mediante el uso de piezas cerámicas de unos $40 \mathrm{~cm}$ de largo, semejantes a tejas pero con un ángulo mucho más agudo que les otorga un fondo de $11 \mathrm{~cm}$ y una anchura próxima a los $10 \mathrm{~cm}$ (Figura 11). En este caso, las piezas se asientan sobre una capa de mortero de grano medio sin que las mismas hayan sido aparentemente cubiertas en ningún momento, es decir, parece que se trataba de una canalización a cielo abierto. Sin duda, el marcado ángulo de las piezas cerámicas es lo más llamativo de esta conducción, particularidad que apenas fue utilizada en otros sistemas hidráulicos ante la falta de referencias al respecto.

El estado de conservación de las tres conducciones es bastante deficiente, aunque aún quedan suficientes evidencias físicas que permiten dilucidar su discurrir por la margen izquierda de la rambla hasta las parcelas que antaño fueron cultivadas por Nicolás Dato Rosique en el fondo de la rambla. Del mismo modo, según el trazado de las mismas, es muy posible que alguna de estas canalizaciones vertiese sus aguas en el abrevadero edificado en las inmediaciones del punto por el que el camino cruza la rambla. Este receptáculo, de 1'80 m de largo por 1'50 m de ancho, debió abastecer a los rebaños de la población local y, a día de hoy, se encuentra en un estado aceptable de conservación. Por otro lado, es probable que existiera una conexión entre alguna de estas canalizaciones y el antedi- 
cho abrevadero, por la cota de ambos elementos hidráulicos, es posible que, igualmente, abasteciesen en una época pasada a la balsa de la Casa de la Fuente.

La falta de información acerca de las tres conducciones se ha intentado suplir con el análisis de paralelos a nivel nacional y regional, si bien los resultados ofrecen un periodo cronológico muy amplio. Sin embargo, a modo de mera nota informativa y sin que suponga una datación cronológica debido a la necesidad de estudios arqueológicos que arrojen luz a esta cuestión, cabe decir que el empleo de piezas cerámicas, tejas y atanores como técnica de conducción, fue una solución utilizada en canalizaciones datadas desde época romana hasta el siglo XX. La escasa pero constatada presencia de fragmentos de época romana y la presencia en el entorno de yacimientos datados tanto en esta época como en el periodo musulmán, podrían hacernos retrotraer el origen primigenio del aprovechamiento de esta captación a unas épocas tan lejanas como estas. Si bien, a falta de exploraciones arqueológicas y una documentación que lo acredite, no hay que obviar que esta misma solución técnica fue aplicada en época medieval y en épocas mucho más recientes. No obstante, estas son tan solo hipótesis que quedan únicamente expresadas como posibilidades a tener en cuenta, ante la falta de evidencias científicas que permitan establecer una datación concreta.

\section{CONCLUSIONES}

Tanto los restos arquitectónicos existentes como la documentación histórica consultada, permiten señalar que la Fuente del Alacrán fue un manantial aprovechado desde época histórica para uso agrícola, ganadero y humano. La presencia de hasta cuatro sistemas que captaban y canalizaban las aguas que pudieran manar de forma natural del lecho de la rambla o aquellas filtradas a la mina, atestiguan un uso prolongado de los sistemas, en un territorio donde la disponibilidad de agua suponía un elemento claro de supervivencia vital ante las escasas precipitaciones.

El trabajo de campo y el análisis archivístico únicamente han posibilitado discernir el origen del sistema compuesto por la galería filtrante o mina construida por Nicolás Dato Rosique a mediados del siglo XIX, si bien deja abierta la posibilidad de futuras investigaciones encaminadas a dilucidar cuándo, cómo y por qué se llevaron a cabo las otras tres canalizaciones existentes en el lecho de la rambla de la Fuente del Alacrán.

Resulta necesario señalar que, en todo caso, las aguas captadas por el conjunto de sistemas tenían como función abastecer el espacio agrícola existente en las inmediaciones del paraje de Los Brianes, área en la que la disponibilidad hídrica constante a partir de esta captación posibilitó un cultivo más intensivo de las 
propiedades $\mathrm{y}$, de este modo, la acometida de una notable transformación paisajística del entorno. Del mismo modo, es indudable que este mismo manantial se convirtió en un punto de abasto humano y ganadero de especial importancia, garantizando con ello tanto la propia supervivencia de los vecinos de Corvera y caseríos limítrofes como de los rebaños existentes o aquellos que elegían este camino de paso en sus desplazamientos hacia pastos más atractivos.

Las características físicas de cada uno de los sistemas que recogían y conducían las aguas de la citada rambla, muestran una complejidad estructural y una adaptación al medio admirable. Llaman la atención no sólo las diferentes soluciones técnicas y arquitectónicas empleadas, sino la eficiencia y variedad de las mismas en un espacio tan reducido. Diferencias que, en sí mismas, pueden ser la clave para catalogar cronológicamente estas canalizaciones construidas con los recursos que el propio entorno ofrecía y, por tanto, claros ejemplos de arquitectura vernácula y del aprovechamiento de los ínfimos caudales presentes en el área de análisis.

El estudio de todas y cada una de las técnicas aplicadas tradicionalmente en los medios semiáridos para obtener recursos hídricos es especialmente relevante para conocer cómo nuestros antepasados se adaptaron al medio y solventaron estas carencias naturales del territorio sobre el que se asentaron desde hace siglos. El análisis de la Fuente del Alacrán, supone el reconocimiento de otro sistema de captación de aguas subálveas mediante mina filtrante que se añade al catálogo ya existente, permitiendo con ello establecer comparaciones tanto técnicas como temporales con otros sistemas presentes en esta misma comarca del Campo de Cartagena y en otras de la Región de Murcia.

\section{BIBLIOGRAFÍA}

Alcaraz Quiñonero, J.: «Prensa gráfica murciana en el siglo XIX», Anales de Historia Contemporánea, 12, 1966, pp. 551-560.

Aranda Mercader, J. D.: Conoce el oeste, Cartagena: ETSIA (UPCT), 2014, $2^{\text {a }}$ edición.

Belda Navarro, C.; Hernández Albaladejo, E.: Arte de la Región de Murcia: de la Reconquista a la Ilustración, Murcia: Consejería de Educación y Cultura, Secretaría General, Servicio de Publicaciones y Estadística, 2006.

Belda Navarro, C.: El proceso de romanización de la provincia de Murcia. Murcia: Consejo Superior de Investigaciones Científicas (CSIC), 1975.

CAstejón Porcel, G.: «Galerías con lumbreras y presas subálveas como sistema drenante de áreas palúdicas en Fuente álamo de Murcia (SS. XVIII-XIX)» en J. de la Riva, P. Ibarra, R. Montorio y M. Rodrigues (eds.), Análisis espacial 
y representación geográfica: innovación y aplicación, Zaragoza: Universidad de Zaragoza, AGE, 2015, pp. 59-68.

CAstejón Porcel, G.: Galerías con lumbreras (qanats) en Fuente Álamo de Murcia: sistemas históricos de captación y canalización de aguas, Fuente Álamo de Murcia: Ayuntamiento de Fuente Álamo de Murcia, 2014.

CAstejón Porcel, G.: «Galerías con lumbreras en Fuente Álamo de Murcia: Los sistemas de la Casa de Girón (SS. XVIII-XXI)», en Irrigation, Society, Landscape. Tribute to T. F. Glick, Valencia: Universidad de Valencia, 2014. (Póster).

Egea Vivancos, A.; Arias Ferrer, L.: «El abastecimiento de agua a la ciudad de Cartagena en época moderna: Los manantiales de San Juan, la Cruz, el Calvario y el Barranco del Feo a la luz de los textos y la arqueología», Revista Murciana de Antropología, 14, 2007, pp. 259-282.

GARcía PÉrez, F. J.: Visita del obispo Sancho Dávila a la catedral de Murcia: año 1592, vol. 1, Murcia: Universidad de Murcia, 1980.

García BlánqueZ, L. A.: «Aprovisionamiento hidráulico romano en el Ager Carthaginensis. Estructuras hidráulicas de almacenaje y depuración», AnMurcia, 25-26, 2009-2010, pp. 213-255.

Gómez Espín, J. M.; Castejón Porcel, G.; Gil Meseguer, E.: «Un modelo de captación y conducción de aguas en medios semiáridos: El Canal del Sifón en Fuente Álamo de Murcia», en Patrimonio hidráulico y cultura del agua en el Mediterráneo, Murcia: Fundación Séneca, Campus Mare Nostrum y AECID, 2012, pp. 227-248.

Gómez Espín, J. M.; Gil Meseguer, E., Martínez Medina, R.; López FERNÁNDEZ, J. A.: «Las estructuras de captación de agua mediante galerías con lumbreras en el Campo de Cartagena», Revista Murciana de Antropología, 14, 2007, pp. 161-193.

Instituto Geográfico y Estadístico (IGE): Nomenclátor de las ciudades, villas, lugares, aldeas y demás entidades de población de España en $1^{\circ}$ de enero de 1888, 8 v. Biblioteca Nacional de España: Biblioteca Digital Hispánica, 1892-1895.

López Fernández, J. A.; Gómez Espín, J. M.: «Abastecimientos tradicionales de agua a los municipios de Mula, Pliego y Bullas (Región de Murcia)», Nimbus: Revista de climatología, meteorología y paisaje, 21, 2008, pp. 133-152.

MARTínez HERnÁNDEZ, C.: «Aprovechamiento tradicional y expectativas turísticas de los ingenios hidráulicos en la cabecera de la Rambla del Mingrano», en R. García Marín, F. Alonso Sarría, F. Belmonte Serrato, D. Moreno Muñoz, (eds.), XV Coloquio Ibérico de Geografía. Retos y tendencias de la Geografia Ibérica, Murcia: AGE, 2016. 
Mas BelÉn, B.: «La aldea de La Murta bajo la advocación de la Santa Cruz y los canteros murteños entre los siglos XIX y XX», Revista Murciana de Antropología, 19, 2012, pp. 81-92.

Molina MolinA, A. L.: El Campo de Murcia en el siglo XV, Murcia: Academia Alfonso X El Sabio, 1989.

Owens, J. B.: Rebelión, monarquía y oligarquía murciana en la época de Carlos $V$, Murcia: Universidad de Murcia, 1980.

PÉrez PÉrez, E.: «Disposiciones decimonónicas sobre aguas: ley de 1879», en A. Gil Olcina, A. Morales Gil (coords.), Hitos históricos de los regadios españoles, Madrid: Ministerio de Agricultura, Alimentación y Medio Ambiente, Secretaría General Técnica, 1992, pp. 183-202.

Rabal Saura, G.; Castejón Porcel, G.: «Cazoletas y canalillos en el piedemonte de la solana de las Sierras de Carrascoy-El Puerto (Murcia, España)», Revista Cuadernos de Arte Prehistórico, 5, Moratalla: Centro de Arte Rupestre Moratalla, 2018, pp. 121-148.

Ramallo Asensio, S. F.; Arana Castillo, R.: Canteras romanas de Carthago Nova y alrededores (Hispania Citerior), Murcia: Universidad de Murcia, 1987, pp. 33-36.

RodríGuez Llopis, M.; García DíAz, I.: Iglesia y sociedad feudal. El cabildo de la Catedral de Murcia en la Baja Edad Media, Murcia: Universidad de Murcia, 1994.

SÁnchez Martínez, M.: «Las aguas de Lobosillo», Revista Murciana de Antropología, 14, 2007, pp. 603-632.

TORRES Fontes, J.: Repartimiento de Murcia, Murcia: CSIC, Escuela de Estudios Medievales y Academia Alfonso X El Sabio, 1960. 